\title{
Effect of anthelmintic treatment strategy on strongylid nematode species composition in grazing lambs in Scotland
}

\author{
Lynsey A Melville ${ }^{1 *}$, David McBean ${ }^{1}$, Alex Fyfe ${ }^{1}$, Sara-Jane Campbell ${ }^{1}$, Javier Palarea-Albaladejo ${ }^{2}$ and Fiona Kenyon ${ }^{1}$
}

\begin{abstract}
Background: Refugia based anthelmintic protocols aim to reduce the rate of development of anthelmintic resistance in gastrointestinal nematodes (GIN). Previous studies have illustrated the impact of different drenching regimes on drug efficacy and animal growth; however, the impact on nematode populations has yet to be characterised within natural infections. This study investigated the changes in species composition of GIN throughout the grazing season, following implementation of four different ivermectin drenching regimes over six years: neo-suppressive monthly treatment (NST), targeted selective treatment (TST), strategic prophylactic treatment (SPT) and treatment upon observation of clinical signs (MT).
\end{abstract}

Methods: Lambs were grazed on one of eight replicate paddocks each grazing season following treatment regimes assigned in year 1. Faecal samples were collected fortnightly from all animals and hatched to first stage larvae $\left(L_{1}\right)$. DNA was extracted from individual $L_{1}$ and a multiplex PCR assay targeting the internal transcribed spacer 2 (ITS2) region of Teladorsagia circumcincta, Trichostrongylus spp. and Haemonchus contortus conducted. Other species were identified using species-specific PCR. Worm-naïve tracer lambs were grazed on the paddocks at the start and end of each grazing season and adult worms recovered at post mortem to investigate the parasite population on pasture.

Results: Results showed an overall decrease in species diversity in egg output from the NST group which occurred within a single grazing season and was consistent throughout the experiment. Species diversity was protected over six years in groups implementing TST, SPT and MT treatment regimes, designed to offer refugia. The expected shift in species prevalence throughout the season from Teladorsagia to Trichostrongylus was observed in all but the NST group where only Teladorsagia spp. were recovered from trial lambs by the end of the experiment. Worm burdens indicated the presence of several species at relatively low abundance on pasture in the NST group in 2011. However, these species were not represented in egg output from trial lambs, probably due to the frequent anthelmintic treatment administered throughout the grazing season.

Conclusion: The molecular methods utilised here worked well. The comparable results of the three refugia-based treatment regimes suggest that nematode diversity can be maintained using part or whole group treatments if a rich supra-population of parasites are available to re-infect animals post treatment.

Keywords: Gastrointestinal nematodes, Lambs, Species prevalence, Anthelmintic, Multiplex PCR

\footnotetext{
* Correspondence: lynsey.melville@moredun.ac.uk

${ }^{1}$ Moredun Research Institute, Pentlands Science Park, Bush Loan, Penicuik

EH26 OPZ Scotland, UK

Full list of author information is available at the end of the article
} 


\section{Background}

Gastrointestinal nematodes (GIN) represent some of the most economically important infections of livestock worldwide. GIN encompasses a wide range of parasitic worms found within the digestive tract of their host; symptoms include acute diarrhoea, production losses and ill thrift, causing significant morbidity and sometimes mortality in young livestock. Control of GIN is currently focused on chemotherapeutic treatment with broad spectrum anthelmintics. The repeated and constant use of these chemicals has put significant selection pressure on GIN resulting in the emergence of resistance to several drug classes [1, 2]. Anthelmintic resistance (AR) is now widespread and threatens the future sustainability of the sheep industry worldwide [3]. In the current climate where AR appears to be inevitable, research is now being focused on slowing the development of resistance on farms.

The importance of conserving refugia of drug-naïve parasites to dilute the eggs of resistant worms surviving treatment was first suggested in the 1980s [4, 5] and has since been highlighted as a key factor determining the rate of development of AR. Several studies have demonstrated the benefits of maintaining an un-selected population of parasites in refugia on conservation of drug efficacy over time and slowing the development of AR [6-8] within species. In addition, a longitudinal study on the impact of different drenching patterns on the performance of grazing lambs [8], demonstrated that growth rates of lambs following targeted treatment regimes aimed at conserving parasites in refugia, were comparable with the growth rates of monthly treated animals. Regular monthly suppressive treatments have been shown to reduce species diversity and worm burden over the course of a single grazing season [9]. This study aimed to investigate the impact of four different ivermectin treatment regimes upon parasite composition when implemented over several consecutive years.

\section{Methods}

\section{Ethics statement}

The study was examined and approved by the Moredun Research Institute Experiments and Ethics Committee and was conducted under the legislation of a UK Home Office Licence (reference PPL 60/03899) in accordance with the Animals (Scientific Procedures) Act of 1986.

\section{Experimental design}

The replicated field trials in this study were conducted in each of six consecutive years (2006-2011) at the Moredun Research Institute farm, Scotland.

Parasite material was collected throughout the 2006 and 2011 seasons of the longitudinal field trial described by Kenyon et al. [8], which investigated the impact of four anthelmintic treatment strategies on drug efficacy and production efficiency in grazing lambs. Briefly, replicated field trials were conducted over six consecutive years (2006-2011); each year, 128-192 lambs were split into eight groups (balanced for weight, sex and faecal egg count) which were randomly allocated to eight one hectare paddocks, replicate groups received one of four ivermectin treatment regimes (Oramec, Merial Animal Health Limited, UK at the manufacturer's recommended dose rate of $0.2 \mathrm{mg} / \mathrm{kg}$ live weight). The eight paddocks were randomly assigned to the four treatment groups at the start of the experiment and treatment strategies were maintained on the same paddocks throughout to compare the impact of different treatment regimes on parasite epidemiology over six years. Implementation of the different treatment strategies began on day 56 of each grazing season (apart from TST in 2006 which began on day 98, due to validation of the Happy Factor [10] model in the first year of the experiment). The molecular species data from trial lambs described in this paper were collected from day 56 until the end of the grazing season (day 154) in the 2006 and 2011 seasons, whilst tracer lambs were used to examine contamination on paddocks at the start and the end of the experiment.

\section{Treatment strategies}

Two groups of lambs received a neo-suppressive treatment (NST) regime in which a whole-group drench was administered every four weeks throughout the grazing season. The second treatment strategy was a targeted selective treatment (TST) regime; individual lambs were drenched based upon their ability to reach individualised target weights. These target weights were generated using the Happy Factor $^{\text {тм }}$ decision support model described by Greer et al. [10] which considers environmental factors, food availability and growth rates of individual lambs. The third treatment regime was a strategic prophylactic (SPT) approach where a wholegroup drench was administered twice throughout the grazing season; at weaning and 4 to 6 weeks postweaning. The fourth followed a metaphylactic/therapeutic (MT) treatment strategy; all lambs in both paddocks were drenched only when clinical signs of ill thrift appeared in lambs in either paddock. In 2006, lambs in all treatment groups, except MT, received benzimidazole (Panacur, Intervet at $5 \mathrm{mg} / \mathrm{kg}$ live weight) on day 28 to control for Nematodirus species infection. In 2011, all lambs received benzimidazole on day 7 and ivermectin on day 28 , for the same reasons.

\section{Sample collection}

Two sources of material were used: nematode eggs from faeces collected from trial lambs and worm burdens from tracer lambs. Faecal samples were collected from 
each lamb at 8 time-points throughout the grazing season to give an indication of species output from the host. Two parasite-naive 'tracer' lambs were grazed on each paddock at the start (May) and another two at the end (September) of every grazing season to indicate the number and species of nematode present on pasture.

\section{Nematode egg extraction and DNA extraction}

Faecal samples were collected per rectum from each lamb fortnightly and faecal egg counts (FEC) were conducted following the method of Jackson [11] as described in Kenyon et al. [8]. This FEC method provides a sensitivity of up to one egg per gram of faeces (epg). Nematodirus eggs were differentiated morphologically from other strongylid species and were not included in the results here as this species does not hatch to $L_{1}$.

Following faecal egg counting, the strongylid eggs present in each $1 \mathrm{~g}$ faecal sample were pooled by treatment group, assuming that variability between lambs and paddocks was negligible in accordance with our field experience, to give a pooled representative of the population for each treatment group at each time point. The eggs were washed over a $25 \mu \mathrm{m}$ sieve with tap water to remove the salt, and incubated in a petri dish at $22{ }^{\circ} \mathrm{C}$ for $72 \mathrm{~h}$ to allow the eggs to hatch to the first larval stage $\left(\mathrm{L}_{1}\right)$. Hatching was verified microscopically and larvae were fixed in ethanol (final concentration > $70 \%$ EtOH). Ethanol-fixed $\mathrm{L}_{1}$ were bathed in $1 \mathrm{x}$ phosphatebuffered solution (PBS) $(1 / 100 \mathrm{v} / \mathrm{v})$ for $30 \mathrm{~min}$ to rehydrate larvae. Individual $\mathrm{L}_{1}$ from samples collected on day 56 onwards were picked and placed into each well of a 96 well plate (Axygen), containing $50 \mu \mathrm{l}$ lysis buffer (50 mM KCl, $2.5 \mathrm{mM} \mathrm{MgCl}_{2}, 10 \mathrm{mM}$ Tris (pH 8.3) 0.45 \% Nonidet P-40, 0.45 \% Tween 20, 0.01 \% Gelatine plus $0.1 \mathrm{mg} / \mathrm{ml}$ proteinase K) [12]. Forty-two individual larvae, were randomly selected from the pool for each treatment group at each time point. Plates were placed at $-20{ }^{\circ} \mathrm{C}$ overnight, incubated at $56{ }^{\circ} \mathrm{C}$ for $4 \mathrm{~h}$ then heated to $95{ }^{\circ} \mathrm{C}$ for $15 \mathrm{~min}$ to deactivate the proteinase $\mathrm{K}$. DNA was precipitated by adding $100 \mu \mathrm{l}$ ethanol to each well; plates were kept a $-20{ }^{\circ} \mathrm{C}$ overnight and centrifuged $\left(4000 \mathrm{~g}, 40 \mathrm{~min}\right.$ at $\left.4{ }^{\circ} \mathrm{C}\right)$. Supernatant was removed and plates were air-dried briefly. Extracted DNA was then re-suspended in $50 \mu \mathrm{l}$ of DNA-free water.

\section{Worm burdens from tracer lambs}

As described by Kenyon et al. [8], tracer lambs were grazed for 28 days then housed for two weeks before euthanisation. Abomasa, small intestine and large intestine were recovered from each animal. Each organ was opened longitudinally, placed in $5 \mathrm{~L}$ of physiological saline $(0.85 \%$ sodium chloride $\mathrm{w} / \mathrm{v})$ and incubated at $37{ }^{\circ} \mathrm{C}$ for $4 \mathrm{~h}$, following which the mucosa was washed into the saline and the organ removed. A $10 \%$ sub-sample was collected from each organ and immediately fixed in $2 \%$ formalin [13].

\section{Species identification}

Species were identified for trial lambs from each of the $42 \mathrm{~L}_{1}$ from the pool for each treatment by time point using multiplex PCR or species specific PCR (see below). For each tracer lamb, the worms present in a $2 \%$ organ digest sub-sample were counted and differentiated by developmental stage and sex and approximately 25 males were then cleared using lactophenol (GCC Diagnostics, UK) and species identified in light microscopy morphological examination [13].

\section{Multiplex $P C R$}

A published multiplex PCR assay [14] was utilised to identify the five most common nematode species found in this region: Teladorsagia circumcincta, Trichostrongylus vitrinus, Trichostrongylus colubriformis, Trichostrongylus axei and Haemonchus contortus. PCR reactions $(10 \mu \mathrm{l})$ were carried out using Platinum Taq (Invitrogen) containing $1.5 \mathrm{mM} \mathrm{MgCl}, 0.2 \mathrm{mM}$ dNTPs, $0.4 \mathrm{pmol} / \mu \mathrm{l}$ internal transcribed spacer 2 (ITS2) generic primers (ITS2GF, ITS2GR) and $0.3 \mathrm{pmol} / \mu \mathrm{l}$ of each speciesspecific primer (TECIRV1, TRCORV1, TRVIFD1, TRAXFD2, HACOFD2 as described by Bisset et al. [14]. $1.5 \mathrm{ng}$ of genomic DNA template was added to each reaction. Two PCR-negative (no genomic DNA template), two lysis-negative (worm lysis buffer without $L_{1}$ ) and five DNA-positive controls were included in each 96 well plate PCR reaction. Positive control DNA was extracted (Qiagen, DNeasy blood and tissue kit, Hilden, Germany) from morphologically identified adult parasites of the species listed above.

A touchdown PCR cycle was conducted as follows: stage one; initial denaturation at $94{ }^{\circ} \mathrm{C}$ for $8 \mathrm{~min}$ followed by 12 cycles of $94{ }^{\circ} \mathrm{C}$ for $10 \mathrm{~s}, 60-54{ }^{\circ} \mathrm{C}$ (decreasing by $0.5{ }^{\circ} \mathrm{C}$ per cycle) for $15 \mathrm{~s}$ (annealing) and $72{ }^{\circ} \mathrm{C}$ for $30 \mathrm{~s}$ (extension). Stage two comprised 25 cycles of $94{ }^{\circ} \mathrm{C}$ for $10 \mathrm{~s}, 54{ }^{\circ} \mathrm{C}$ for $15 \mathrm{~s}$ and $72{ }^{\circ} \mathrm{C}$ for $30 \mathrm{~s}$, followed by a final extension phase of $72{ }^{\circ} \mathrm{C}$ for $7 \mathrm{~min}$. PCR products were analysed by QIAxcel advanced capillary electrophoresis using the QIAxcel DNA High resolution kit (Qiagen, Hilden, Germany) following the manufacturers' protocol. Analysis was completed using QIAxcel ScreenGel software (Qiagen, Hilden, Germany).

\section{Species-specific PCR}

Multiplex PCR included pan-nematode ITS2 primers in addition to the five species-specific primers to highlight the presence of DNA from nematode species not included in the assay. Species-specific PCR reactions were used to screen samples which amplified only a pan ITS2 band for Chabertia ovina, Oesophagostomum venulosum 
and Cooperia curticei (Table 1). As eggs of Trichuris ovis do not hatch until reaching the predilection site, this species was not included in the assays described. All species-specific PCR reactions were performed using NovaTaq Hot Start master mix (Merck, New Jersey, USA) in $10 \mu \mathrm{l}$ volumes. PCR targeting C. ovina and O. venulosum contained $5 \mu \mathrm{l} 2 \times$ buffer, $3.5 \mathrm{mM}$ $\mathrm{MgCl}_{2}, 1 \mathrm{mM}$ of each primer, $1.5 \mathrm{ng}$ target DNA and $\mathrm{ddH}_{2}$. PCR targeting C. curticei contained $5 \mu \mathrm{l} 2 \times$ buffer, $1.5 \mathrm{mM} \mathrm{MgCl} 2,0.2 \mathrm{mM}$ of each primer, $1.5 \mathrm{ng}$ target DNA and $\mathrm{ddH}_{2} \mathrm{O}$. Reactions were incubated at $94{ }^{\circ} \mathrm{C}$ for $10 \mathrm{~min}$ followed by 35 cycles of $94{ }^{\circ} \mathrm{C}$ for $30 \mathrm{~s}$, PCR-specific annealing temperature (Table 1) for $30 \mathrm{~s}$ and $72{ }^{\circ} \mathrm{C}$ for $30 \mathrm{~s}$, followed by a final extension phase at $72{ }^{\circ} \mathrm{C}$ for $10 \mathrm{~min}$. All PCR products were run on a $2 \%$ agarose gel stained with gel red (Bioline, London, $\mathrm{UK}$ ) and visualised under UV illumination.

\section{Statistical analysis}

Multispecies abundance data (six species: Te. circumcincta, $T r$. vitrinus, $T r$. colubriformis, $H$. contortus, $C$. ovina and $O$. venulosum) were obtained from the $42 \mathrm{~L}_{1}$ as described above. The relationships between these pooled abundance profiles and the year (2006, 2011), grazing season (split into two periods: < 105 (mid) and $>105$ days (late)) and treatment (NST, MT, SPT and TST) factors were explored by fitting a multivariate regression tree (MRT) [15]. The MRT was based on repeated splitting of the abundance profiles into homogenous groups, according to the categories of the given factors, until an optimal partition was reached which minimized the within-group dissimilarities. These latter were measured by the sum of squared Euclidean distances of the abundance profiles about the group mean abundances (centroids). Equivalently, this maximized the sum of squared Euclidean distances between group centroids. The resulting partition was graphically displayed as a tree-like structure that reveals the relative importance of the factors from top to bottom.

Adult worm burdens from the 4 tracer lambs (2 lambs per paddock) at each stage of grazing for each treatment were modelled using generalised linear models
(GLMs) with negative-binomially distributed errors and logarithmic link function. Note that preliminary assessment revealed that fitting a paddock random effect was not needed. We focused on the two most relevant species for which richest data were available (Te. circumcincta, Tr. vitrinus). The factors year $(2006,2011)$, season (early, late), treatment (NST, MT, SPT and TST) and interactions between them were entered as fixed effects in initial models for both species. The final GLM for Te. circumcincta included year, season, treatment and all their two-way interactions as statistically significant factors. The final GLM for Tr. vitrinus included season as the only statistically significant explanatory factor. Model selection was based on likelihood ratio tests and the usual $5 \%$ threshold was used for concluding statistical significance.

All statistical analyses were conducted using the $\mathrm{R}$ system for statistical computing v3.2 [16].

\section{Results}

Species composition of $L_{1}$ from faecal samples

Figure 1 shows the percentage of each species identified from each of the eight sampling periods in 2006 and 2011 from trial lambs in each of the four treatment groups.

In 2006, there was a range of strongylid species present in all treatment groups during the season. The predominant species in all groups at day 56 of the experiment was Te. circumcincta, which accounted for $100,100,90.4$ and $67.6 \%$ of $\mathrm{L}_{1}$ recovered from faecal samples in the NST, TST, SPT and MT group, respectively. Later in the season, a greater variety of nematode species were identified. Trichostrongylus vitrinus was the predominant species from day 98 in the MT group and day 112 in the TST and SPT groups, comprising 80, 56 and $67 \%$ of strongylid larvae, respectively. Other species were found to a lesser extent and varied between groups; for example, C. ovina was present in the TST group in mid-season, was not observed in the SPT group and was rare in the MT group. Haemonchus contortus was identified at two sampling points, day 140 in the SPT group and day 126 in the MT group. In comparison, Te. circumcincta

Table 1 Primer sequences and annealing temperatures (Ta) for species-specific PCR reactions

\begin{tabular}{|c|c|c|c|c|c|}
\hline Species & Primer & Sequence & Ta & Product size & Reference \\
\hline \multirow[t]{2}{*}{ Chabertia ovina } & $\mathrm{CHO}$ & GATGACCTCGTTGTCACCGTG & $55^{\circ} \mathrm{C}$ & $162 \mathrm{bp}$ & [30] \\
\hline & NC2 & TAAGTTCTTITCCTCCGCT & & & \\
\hline \multirow[t]{2}{*}{ Oesophagostomum venulosum } & OEV & TGAAATGAGACAACCGTAGTCG & $55^{\circ} \mathrm{C}$ & $105 \mathrm{bp}$ & [30] \\
\hline & NC2 & TTAGTTTCTTTCCTCCGCT & & & \\
\hline \multirow[t]{2}{*}{ Cooperia curticei } & $\mathrm{CCF}$ & TATACTACAGTGTGGCTAGCG & $52^{\circ} \mathrm{C}$ & 143 bp & [17] \\
\hline & $C C R$ & TCATACCATTCAGAAATGTTC & & & \\
\hline
\end{tabular}



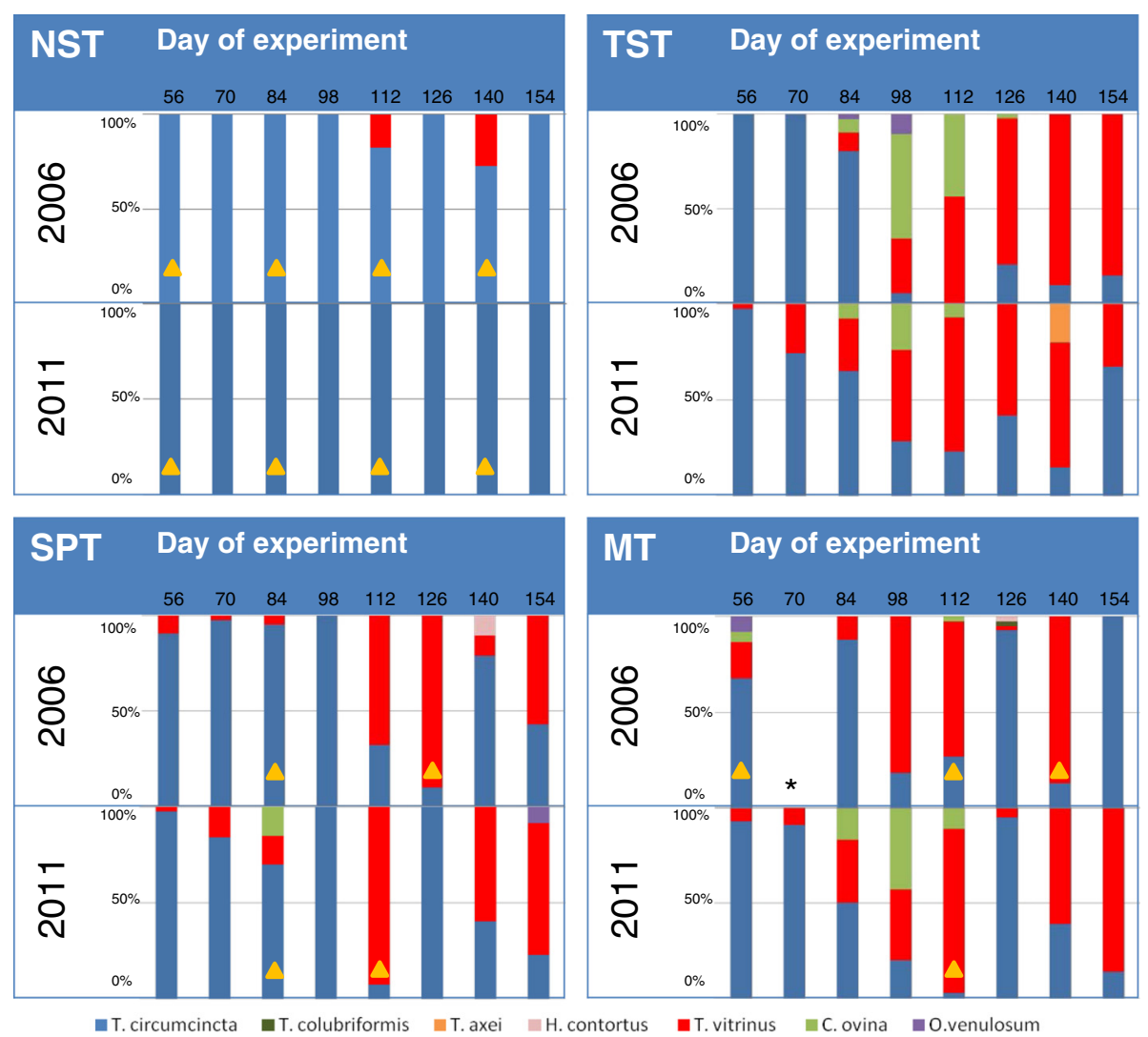

Fig. 1 Species composition (\%) of first stage larvae $\left(L_{1}\right)$ hatched from faecal samples collected from trial lambs from Neosupressive (NST), Targeted Selective (TST), Strategic prophylactic (SPT) and Metaphylactic/therapeutic (MT) treatment groups during the grazing seasons in 2006 and 2011. *No sample available for 2006, day 70 MT group. Yellow triangle, Ivermectin treatments administered to all lambs in the treatment group. In both years, varying numbers of lambs were drenched in the TST group, according to their ability to meet individualised predicted weight gain targets, see Table 3

continued to dominate in the NST group, with the only other species identified being Tr. vitrinus observed on day 112 and 140 of the experiment, with a relative abundance of 17.5 and $27.5 \%$ respectively.

In 2011, the species composition of samples collected from the TST, SPT and MT groups were broadly similar to those observed in 2006, except that $T r$. vitrinus appeared earlier in the season, from day 56 onwards. Chabertia ovina and Oesophagostomum venulosum were observed in the SPT and TST groups, but were absent from the MT group. In contrast, only Te. circumcincta was identified from the $\mathrm{L}_{1}$ collected from faecal samples of NST group lambs. Trichostrongylus axei was not identified in any group at any point.

Figure 2 displays the tree-like grouping structure resulting from the MRT analysis. Three homogenous groups were distinguished with the splits based only on treatment and season. The barplots at the terminal nodes represent the mean species distributions per group. The main distinction was due to treatment, placed on the top node of the tree, with the strong dominance of Te. circumcincta (mean prevalence of $97.1 \%$ ) and the minimal presence of any other species (only $\mathrm{Tr}$. vitrinus, mean prevalence of $2.9 \%$ ) in the abundance profiles resulting from the NST treatment determining the first split (19\% reduction in withingroup dissimilarity). The other three treatments (MT, SPT and TST) formed a separate homogeneous group of abundance profiles, which was only further split according to season $(30.5 \%$ reduction in within-group dissimilarity). In the mid-season, Te. circumcincta was the dominant species, accounting on average for $77.2 \%$ of $\mathrm{L}_{1}$ passed out onto pasture, whereas Tr. vitrinus, C. ovina and O. venulosum accounted for $14.2 \%, 7.6 \%$ and $0.9 \%$ of $\mathrm{L}_{1}$, respectively. Finally, in the group at the rightmost terminal node, which corresponds to cases under treatment MT, SPT or TST and late season, a more varied range of species was found. The mean relative abundances of the observed species were $36.9 \%$ Te. circumcincta, $58.8 \% \mathrm{Tr}$. vitrinus, $0.1 \%$ Tr. colubriformis, $0.3 \%$ H. contortus, $2.7 \%$ C. ovina and $1.2 \%$ O. venulosum. 


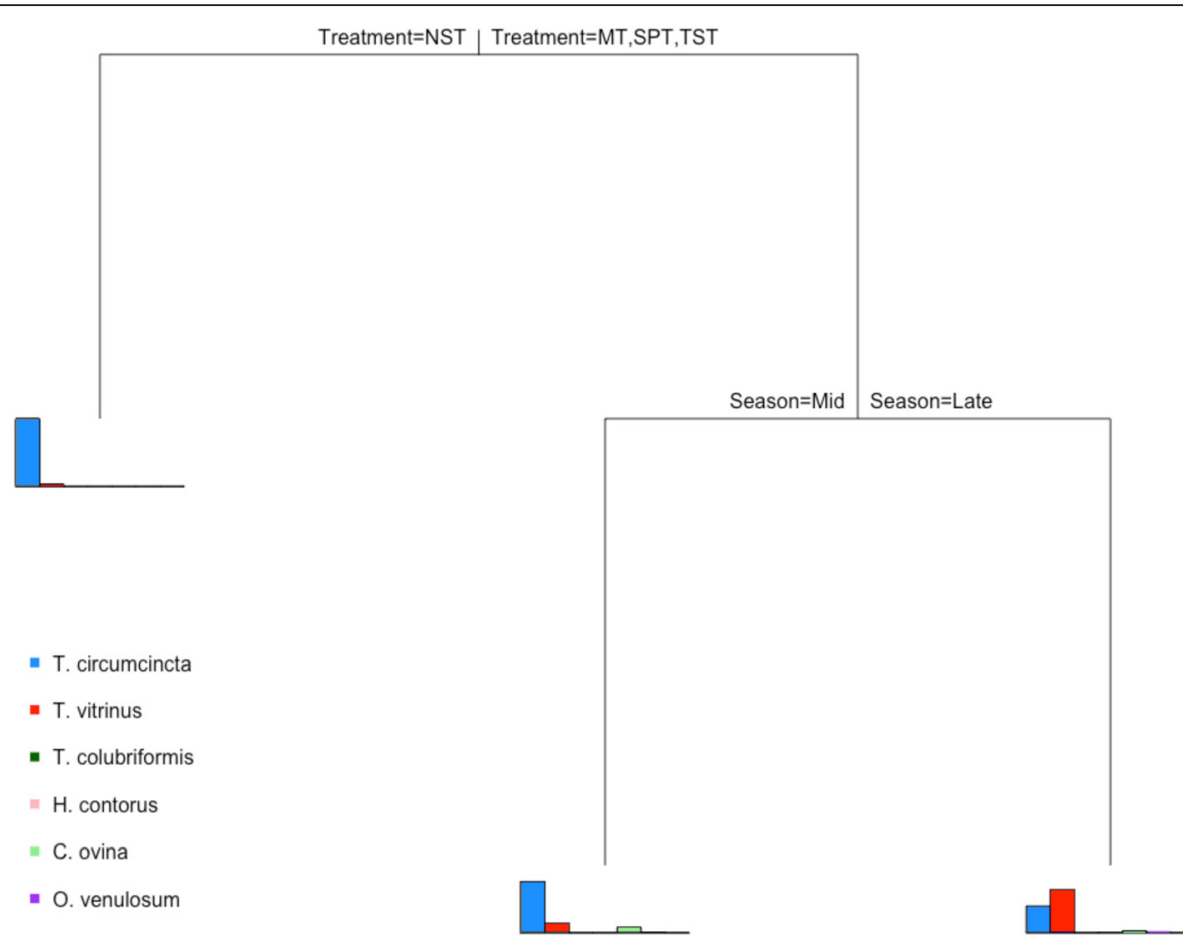

Fig. 2 Multivariate regression tree showing the hierarchical structure of homogeneous groups of species abundance profiles of first stage larvae $\left(L_{1}\right)$ hatched from faecal samples collected from trial lambs when comparing by years, seasons and treatment groups. The bar plots at the terminal nodes show the mean species composition of each of the three groups differentiated according to treatment and season

\section{Species composition of adult worms recovered from tracer lambs}

Table 2 shows the mean totals and percentage species composition of adult worms identified from the tracer lambs which had grazed the respective paddocks. The most prevalent nematode species in the TST, SPT and MT groups was Te. circumcincta, accounting for $47.9 \%$, $73.1 \%$ and $81.1 \%$ of the strongylid nematodes recovered, respectively. Teladorsagia circumcincta comprised $25 \%$ of worms recovered from the NST group early 2006 tracer lambs; the most prevalent nematode species in this group were $T r$. vitrinus and $T$. ovis, comprising 28.1 and $26.4 \%$ of worms, respectively. Species composition in late 2006 remained similar in all groups with the exception of NST in which Tr. vitrinus was reduced in relative terms, comprising $15.2 \%$ of the total worm burden compared to 50.6, 44.3 and $45.8 \%$ in the TST, SPT and MT groups, respectively. Comparison of total worm burdens from the late season tracer lambs in 2006 and 2011 indicated an increase in pasture contamination over the course of the study in the NST and MT groups and a reduction in the TST and SPT groups.

Differences between the treatment groups were evident in worm burdens collected from tracer lambs grazing on the paddocks at the beginning of the grazing season in 2011. The most predominant GIN species was still Te. circumcincta, comprising 94.8, 52.2, 70.2 and $79.8 \%$ of total worm burden in NST, TST, SPT and MT groups, respectively. Species diversity was similar to that found in early 2006 for TST, SPT and MT groups; however, a reduction in the relative abundance of the large intestinal species (O. venulosum and C. ovina) was observed in all groups, from being present at low prevalences in early season 2006 (range 4.3-31.1 for both species over the 3 groups) to $1 \%$ or less in early season 2011. Worm burdens recovered from tracer lambs grazed on NST pastures in 2011 showed that the nematode population on these pastures was more diverse than expected from the data obtained from the egg output (Fig. 1). Although Te. circumcincta was by far the most prevalent species, accounting for over $94 \%$ of the worms identified in the NST group, Tr. vitrinus, Tr. axei and $C$. ovina were also identified at low relative abundance.

Focusing on Te. circumcincta, statistically significant interaction effects of treatment group with year $\left(\chi^{2}=8.95\right.$, $d f=3, P=0.030)$ and season $\left(\chi^{2}=14.52, d f=3, P=0.002\right)$ on the mean abundance of Te. circumcincta were found. Statistical comparison in 2006 worm burdens revealed no statistically significant overall differences between treatment groups regardless of the season $\left(\chi^{2}=5.22, d f=3\right.$, $P=0.157)$. However, overall Te. circumcincta burdens 
Table 2 Mean ( \pm SEM) total worm burden and mean percentage prevalence of strongylid species present over four tracer lambs in each of the 4 treatment groups and each year and season of the study. '-'means that the species was not present

\begin{tabular}{|c|c|c|c|c|c|c|c|c|c|c|}
\hline Group & Year & Season & Total worm burden & \%Te. circ & $\% \operatorname{Tr}$. axei & $\%$ Tr. vit & $\% \operatorname{Tr} . \mathrm{col}$ & $\%$ O. ven & \% C. ovina & $\%$ T. ovis \\
\hline \multirow[t]{4}{*}{ NST } & 2006 & Early & $1488( \pm 597)$ & 25.0 & - & 28.1 & - & 8.8 & 11.7 & 26.4 \\
\hline & & Late & $12,184( \pm 4473)$ & 79.9 & 4.1 & 15.2 & - & - & - & 0.8 \\
\hline & 2011 & Early & $2594( \pm 774)$ & 94.8 & 1.7 & 2.5 & - & - & 1.0 & - \\
\hline & & Late & $23,954( \pm 3942)$ & 94.1 & 2.2 & 3.8 & - & - & - & - \\
\hline \multirow[t]{4}{*}{ TST } & 2006 & Early & $2537( \pm 1206)$ & 47.9 & - & 7.7 & - & 9.8 & 31.1 & 3.5 \\
\hline & & Late & $36,317( \pm 20,307)$ & 48.6 & 0.8 & 50.6 & - & - & - & - \\
\hline & 2011 & Early & $5929( \pm 2277)$ & 52.2 & - & 47.8 & - & - & - & - \\
\hline & & Late & $14,586( \pm 3436)$ & 63.9 & - & 36.1 & - & - & - & - \\
\hline \multirow[t]{4}{*}{ SPT } & 2006 & Early & $1548( \pm 1151)$ & 73.1 & - & 7.3 & - & - & 5.9 & 13.7 \\
\hline & & Late & $41,182( \pm 20,304)$ & 54.8 & - & 44.3 & - & 0.9 & - & - \\
\hline & 2011 & Early & $2770( \pm 955)$ & 70.2 & - & 29.8 & - & - & - & - \\
\hline & & Late & $27,740( \pm 4259)$ & 73.3 & 0.7 & 25.9 & - & - & - & 0.1 \\
\hline \multirow[t]{4}{*}{ MT } & 2006 & Early & $9016( \pm 3408)$ & 81.1 & - & 7.1 & 0.3 & 5.7 & 4.4 & 1.4 \\
\hline & & Late & $19,181( \pm 7313)$ & 53.6 & - & 45.8 & - & - & - & 0.5 \\
\hline & 2011 & Early & $9694( \pm 2393)$ & 79.8 & - & 20.2 & - & - & - & - \\
\hline & & Late & $37,834( \pm 7184)$ & 40.4 & 0.4 & 58.9 & - & 0.2 & - & 0.1 \\
\hline
\end{tabular}

recovered from tracer lambs grazed on the pasture at the end of 2006 were significantly higher in the late season $\left(\chi^{2}=45.96, d f=1, P<0.001\right)$. In 2011 , a significant interaction between treatment group and season was found $\left(\chi^{2}=19.01, d f=3, P<0.001\right)$. In early 2011 , statistically significant differences between group means were found $\left(\chi^{2}=14.23, d f=3, P=0.003\right)$. The overall relative abundance of Te. circumcincta in the NST group increased from 2006, reaching a mean level in comparison with the other groups in $2011\left(\chi^{2}=8.95, d f=3, P=0.030\right)$; however Te. circumcincta populations remained stable in the TST, SPT and MT groups between years.

With regard to $T r$. vitrinus, only a statistically significant effect of season was found $\left(\chi^{2}=17.36, d f=1, P<0.001\right)$, with a higher predicted mean overall worm burden, as expected, at late season: 7800 [CI: 4074.52-14931.84] versus 860.05 [CI: 449.20-1646.66]).

\section{Effect of anthelmintic drenching}

The timings of whole-group anthelmintic drenching are shown for the NST, SPT and MT groups in Fig. 1. The proportion of the TST group treated at each sampling point is shown in Table 3. In 2006, only Te. circumcincta was observed from the cultured $\mathrm{L}_{1}$ post ivermectin administration in the NST group. In the SPT and MT groups, anthelmintic use changed the species composition so that Te. circumcincta predominated, however other species continued to be present at a low relative abundance at some time points. The species composition in the TST group did not show a defined change in species composition (Fig. 1), even when $69 \%$ of the group was drenched (see Table 3).

In 2011, only Te. circumcincta was identified pre- and post-drenching from the NST group. Drenching in the SPT group, resulted in only Te circumcincta being identified, and in the MT group the species dynamics switched from predomination of Tr. vitrinus to predomination of Te. circumcincta. Again, no obvious change in species composition was observed in the TST group, even after drenching over $50 \%$ of the group on days 112 and 140 .

\section{Discussion}

The aim of this study was to determine the impact of anthelmintic treatment strategy on ovine nematode species composition. Samples were collected to allow the examination of the strongylid nematode species passed out from the host ( $\mathrm{L}_{1}$ cultured from faeces) and of those present on pasture that were available to infect the hosts (adult worms from worm-naïve tracer lambs) in an attempt to determine the impact of different ivermectin

Table 3 The percentage of lambs in the TST group drenched at each sampling point in 2006 and 2011. TST treatment was implemented from days 98 and 56 onwards in 2006 and 2011, respectively

\begin{tabular}{lllllllll}
\hline Day & 56 & 70 & 84 & 98 & 112 & 127 & 140 & 154 \\
\hline 2006 & - & - & - & 16.7 & 68.8 & 27.1 & 68.8 & 20.8 \\
2011 & 17.9 & 33.3 & 30.8 & 43.6 & 51.3 & 30.8 & 56.4 & 41.0 \\
\hline
\end{tabular}


drenching strategies on species composition. Although the use of $L_{1}$, instead of eggs, could potentially have affected the species composition due to some species not developing whilst in culture, the eggs were cultured for $72 \mathrm{~h}$ which exceeds the 36-48 h stated to obtain maximum $\mathrm{L}_{1}$ hatching rate used by Burgess et al. [17], so we expect that few viable eggs would remain unhatched. Bias could also have been introduced by the selection of 42 larvae for PCR analysis for species identification. This number of larvae was selected to balance sample size with the time and labour costs of picking individual $\mathrm{L}_{1}$ for analysis, which was a requirement of the multiplex PCR methodology [14] used. New species identification methodologies which allow for species identification from pooled samples [18-20] could increase the sample size whilst reducing time required for preparation and analysis.

Species profiles obtained from the tracer lamb worm burdens and $\mathrm{L}_{1}$ from faecal samples were different. However, this is to be expected due to the differences in the samples from which they originate. The adult worm burdens represent the parasite population on pasture, as tracer lambs are parasite naïve, infection with all species present can occur equally. The $\mathrm{L}_{1}$ were obtained from faecal samples collected from trial lambs which have grazed the pasture for the entire season. The $\mathrm{L}_{1}$ species profile represents parasites being passed out onto pasture by the animals and is therefore impacted by several factors including developing immunity in the growing lamb and previous anthelmintic drenches administered.

The pattern of GIN species observed in Scotland is typically Nematodirus spp. in early spring followed by Teladorsagia spp. then Trichostrongylus spp. in late summer [21]. This pattern was replicated in our study with the predominant species being Te. circumcincta in the early to mid-season and Tr. vitrinus becoming more prevalent towards the end of the grazing season in the TST, SPT and MT groups, consistent with previous studies $[17,22]$. Seasonal shifts in species prevalence result from a combination of factors including the development of acquired immunity in lambs $[23,24]$ and environmental shifts in temperature and rainfall impacting the hatching of nematode eggs on pasture [25]. Comparable species profiles were obtained from all treatment groups in the 2006 early season, showing that the populations were similar at the start of the experiment in both species composition and contamination levels. In contrast, there was a marked difference in the prevalence of nematode species identified both from the host and from pasture between the NST and other treatment groups throughout 2011. As all variables except anthelmintic use were similar for all pastures (environmental and stocking conditions etc.), the reasons for this change must be the anthelmintic strategy applied.
There appear to be clear differences in the species composition in egg output of the trial lambs between the anthelmintic treatment groups in 2006, with the NST showing only Te. circumcincta and Tr. vitrinus compared to the TST, SPT and MT groups in which a greater range of species, including the anthelmintic susceptible large intestinal nematodes, was identified. This restriction of species was continued in 2011 in the NST group, with only Te. circumcincta being identified, whereas the other groups maintained a greater number of species. The removal of nematode diversity from the NST group is likely due, in part, to the frequency of anthelmintic treatments administered over each grazing season which is in agreement with Leathwick et al. [9], which showed reduced species diversity in a single grazing season. Fewer anthelmintic drenches were administered to the TST, SPT and MT groups within each grazing season thus, a significantly lower selection pressure was placed upon the parasites in these groups and as a result, species diversity was largely maintained. Coinfections with multiple nematode species, the normal state in sheep, has been found to alter the establishment of various nematode species when compared with single species infections e.g. Te. circumcincta and Tr. vitrinus [26] and thus within-host competition may help to regulate the effects of infection [27]. Monospecific infection has been associated with production limiting disease [28], therefore the maintenance of multi-species infection could be important for effective control.

Ivermectin treatment in all groups resulted in an increase in the proportion of Te. circumcincta in $\mathrm{L}_{1}$ samples in the two weeks post treatment, the predominant species associated with ivermectin resistance in Scotland [29]. Diversity appears to be restored after a four-week period, in all groups apart from NST, presumably due to re-infection from suprapopulation which was shown by worm burdens to retain species diversity. Only Te. circumcincta was identified in post treatment egg output samples in NST, probably as the other ivermectinsusceptible species were cleared by anthelmintic treatments administered early in the season, prior to implementation of the different treatment strategies on day 56. The potential reasons for the rapid (within single season) change in species composition in the NST group was likely due to the frequency of drenching which removed the susceptible nematode species from the host. Furthermore, as these species would be removed early in the season, their ability to re-infect pasture would be reduced, compared to the drug-resistant Te. circumcincta. Indeed, the proportion of Te. circumcincta on pasture increased in the NST group during the course of the study, with over $90 \%$ of the worm population on pasture being Te. circumcincta throughout 2011. The rapid impact of monthly drenching on the GIN population 
within a single grazing season is in agreement with previously published observations [9].

The TST, SPT and MT treatment regimes were designed to maximise refugia by targeting treatment to individual animals that would benefit from drenching or timepoints where the majority of animals would benefit. The presence of a susceptible parasite population in refugia has been highlighted as a key factor in determining the rate of development of AR $[4,5]$. Drug-naïve, unselected parasites in refugia dilute resistant survivors of treatment and thus delay the emergence of AR. IVMsusceptible species such as C. ovina and $T r$. vitrinus were identified in both egg output and worm burden samples collected from the TST, SPT and MT groups in 2011: the conservation of these species over time, especially in the whole-flock treatment groups, confirms that these parasites were surviving in refugia. The impact of whole-group treatments can be seen in the reduction in species diversity detected two weeks post-treatment in the SPT and MT groups (days 84 and 112 respectively, 2006). The species surviving treatment was predominantly Te. circumcincta; however, species diversity was restored four weeks post-treatment through re-infection from the rich population of parasites in refugia. Species diversity was also restored in the NST group following drenches in 2006; however, in 2011, only Te. circumcincta was observed in $\mathrm{L}_{1}$ cultures throughout the grazing season. Trichostrongylus axei, Tr. vitrinus and C. ovina persisted at low levels on pasture in the NST group throughout the experiment; they were identified from NST tracer lambs in 2011. The lack of these species in the $\mathrm{L}_{1}$ cultures is likely due to the frequency of anthelmintic treatments administered preventing successful re-infection of the trial lambs. Given the sampling method used to examine the $\mathrm{L}_{1}$ species composition, it is possible that additional species were present in the NST group trial lambs in very low numbers however, the data illustrates that Te. circumcincta is the prominent species being passed out onto pasture throughout the season, resulting in a greater expansion of this population compared to other species. This is probably due to the fact that drug resistant nematodes that are unaffected by the drench will continue to lay eggs with little or no interruption. However for any drug susceptible nematode species, reinfection will have to occur and the resulting approximately 21 day pre-patent period means that egg output from these species will be delayed in comparison to the drug resistant nematodes. For example, in the NST group it may mean that Te. circumcincta is able to have continuous egg output throughout the whole experimental period, whereas egg output from drug susceptible species will only occur for one of the four weeks between drenches. The relative abundance of Tr. vitrinus in the NST group in 2006 shows a reduction compared to the other three treatment groups. Adult worm burdens collected at the end of the 2011 grazing season confirm that the Tr. vitrinus population is markedly reduced in the NST group, therefore suggesting that the refugia of supraparasites has been reduced in this treatment group over the six years of the experiment.

On average $26 \%$ of lambs were treated at each timepoint in the TST group [8] thus, refugia was maintained both on pasture and within un-treated animals. The part-flock treatment method used in this group would be expected to provide a greater refugia than the wholeflock treatment methods as, in theory, fewer eggs from drench-surviving parasites will be passed out onto pasture and therefore eggs from nematodes surviving treatment would be further diluted. Despite leaving a proportion of the animals untreated at each time point, pasture contamination in the TST group was lower than that of the other treatment groups at the end of the experiment. Species composition of egg output from TST trial lambs appears more uniform however, the overall nematode species composition in 2011 was similar to that of the SPT and MT groups. It can therefore be concluded that refugia can be successfully maintained using a variety of different management approaches.

Kenyon et al. [8] reported a reduction in drug efficacy in all groups by 2010, where efficacies were $62,86,86$ and $83 \%$ for the NST TST, SPT and MT groups, respectively. The predominance of Te. circumcincta post-treatment strongly suggests that IVM resistant Te. circumcincta were present in all treatment groups. Other species present in the 2011 SPT and MT pretreatment samples appear to be successfully removed by each treatment. Larvae of $T r$. vitrinus were identified in small numbers in some SPT and MT post-treatment samples; however, the proportion of larvae of this species is greatly reduced post-treatment and often not detected at all, suggesting that $T r$. vitrinus has not developed resistance to IVM over the period of study. IVM efficacy for each species cannot be reliably calculated due to the sampling method used for species identification. A total of 42 individual larvae were analysed from each treatment at each time point, and whilst this small sub-sample gives an indication of the species composition, it cannot provide a reliable quantification of the prevalence of the individual species. The overall drug efficacy in the TST, SPT and MT groups remained higher than that of the NST group throughout the study [8], likely due to the presence of susceptible parasite species in refugia.

\section{Conclusions}

Anthelmintic resistance is thought to be inevitable in the current parasitic climate due to the repeated and intensive use of chemotherapeutics. This study builds upon the findings of Kenyon et al. [8], highlighting the 
impact of different treatment strategies on refugia of GIN over time, using molecular species identification techniques. Results suggest that frequent whole-group drenches reduce the diversity and number of GIN surviving in refugia, associated with an increased rate of development of AR. The results also show that maintenance of a rich refugia of susceptible parasites can be achieved both by part-flock, targeted selective treatments or strategically-timed whole-group treatments. One of the key factors in reducing the rate of development of AR is the presence of a refugia of drug susceptible parasites. This study has illustrated that this can be successfully achieved through a variety of management strategies.

\section{Abbreviations}

AR: anthelmintic resistance; EPG: eggs per gram; EtOH: ethanol; FEC: faecal egg count; GIN: gastrointestinal nematode; ITS2: internal transcribed spacer 2; IVM: ivermectin; $L_{1}$ : first developmental stage larvae; $M T$ : study group receiving treatment upon observation of clinical signs of ill thrift; NST: study group receiving neo-suppressive monthly treatment; PBS: phosphate-buffered solution; PCR: polymerase chain reaction; SEM: standard error of the mean; SPT: study group receiving strategic prophylactic treatment; Ta: annealing temperature; TST: study group receiving targeted selective treatment.

\section{Competing interests}

The authors declare that they have no competing interests.

\section{Authors' contributions}

LM participated in the molecular species identification and prepared the manuscript. DM carried out collection of samples. AF participated in the molecular species identification. SJC participated in the molecular species identification. JPA carried out statistical modelling of $\mathrm{L}_{1}$ and worm burden multi-species count data. FK designed the experiment and participated in sample collection and preparation of the manuscript. All authors read and approved the manuscript.

\section{Acknowledgements}

This study was funded by the Scottish Government, EU FP6 PARASOL Project (Grant Agreement No. FOOD-CT-2005-022851) and EU FP7 GLOWORM Project (Grant Agreement No. 288975CP-TP-KBBE.2011.1.3-04). The authors would also like to thank Scott Roger, Jim Rayburn, Moredun Bioservices, Frank Jackson, David Bartley, Alison Morrison, Leigh Devin, Yvonne Bartley, Frank Turnbull and Heather Laurie for their help with the practical aspects of the study.

\section{Author details}

'Moredun Research Institute, Pentlands Science Park, Bush Loan, Penicuik EH26 OPZ Scotland, UK. 'Biomathematics and Statistics Scotland, The King's Buildings, Peter Guthrie Tait Road, Edinburgh EH9 3FDScotland, UK.

Received: 23 February 2016 Accepted: 3 April 2016

Published online: 11 April 2016

\section{References}

1. Edwards JR, Wroth R, de Chaneet GC, Besier RB, Karlsson J, Morcombe PW Dalton-Morgan G, Roberts D. Survey of anthelmintic resistance in Western Australian sheep flocks. 1. Prevalence. Aust Vet J. 1986;63:135-8.

2. Keane OM, Keegan JD, Good B, de Waal T, Fanning J, Gottstein M, Casey M, Hurley C, Sheehan M. High level of treatment failure with commonly used anthelmintics on Irish sheep farms. Irish Vet J. 2014;67:16.

3. Kaplan RM. Drug resistance in nematodes of veterinary importance: a status report. Trends Parasitol. 2004;20:477-81.

4. Prichard RK, Hall CA, Kelly JD, Martin IC, Donald AD. The problem of anthelmintic resistance in nematodes. Aust Vet J. 1980;56:239-51.
5. Van Wyk JA. Refugia - overlooked as perhaps the most potent factor concerning the development of anthelmintic resistance. Onderstepoort J Vet. 2001;68:55-67.

6. Waghorn TS, Leathwick DM, Miller CM, Atkinson DS. Brave or gullible: Testing the concept that leaving susceptible parasites in refugia will slow the development of anthelmintic resistance. New Zeal Vet J. 2008;56:158-63.

7. Kenyon F, Greer AW, Coles GC, Cringoli G, Papadopoulos E, Cabaret J, Berrag B, Varady M, Van Wyk JA, Thomas E, Vercruysse J, Jackson F. The role of targeted selective treatments in the development of refugia-based approaches to the control of gastrointestinal nematodes of small ruminants. Vet Parasitol. 2009;164:3-11.

8. Kenyon F, McBean D, Greer AW, Burgess CG, Morrison AA, Bartley DJ, Bartley Y, Devin L, Nath M, Jackson F. A comparative study of the effects of four treatment regimes on ivermectin efficacy, body weight and pasture contamination in lambs naturally infected with gastrointestinal nematodes in Scotland. Int J Parasitol Drugs Drug Resist. 2013;3:77-84.

9. Leathwick DM, Waghorn TS, Miller CM, Atkinson DS, Haack NA, Oliver AM. Selective and on-demand drenching of lambs: impact on parasite populations and performance of lambs. New Zeal Vet J. 2006:54:305-12.

10. Greer AW, Kenyon F, Bartley DJ, Jackson EB, Gordon Y, Donnan AA, McBean DW, Jackson F. Development and field evaluation of a decision support model for anthelmintic treatments as part of a targeted selective treatment (TST) regime in lambs. Vet Parasitol. 2009;164:12-20.

11. Jackson F. New technique for obtaining nematode ova from sheep faeces. Lab Pract. 1974:23(2):65-6.

12. Kwa MSG, Veenstra JG, van Dijk M, Roos MH. Beta-tubulin genes from the parasitic nematode Haemonchus contortus modulate drug resistance in Caenorhabditis elegans. J Mol Biol. 1995;246:500-10.

13. MAFF. Ministry of Agriculture, Fisheries and Food, Manual of veterinary parasitological laboratory techniques, Reference Book 418, (Her Majesty's Stationery Office. 1986

14. Bisset SA, Knight JS, Bouchet CLG. A multiplex PCR-based method to identify strongylid parasite larvae recovered from ovine faecal cultures and/or pasture samples. Vet Parasitol. 2014:200:117-27.

15. De'ath G. Multivariate regression trees: a new technique for modelling species-environment relationships. Ecology. 2002:83:1105-17.

16. R Core Team. R: A language and environment for statistical computing. Vienna: R Foundation for Statistical Computing; 2015. http://www.R-project.org/.

17. Burgess CG, Bartley Y, Redman E, Skuce PJ, Nath M, Whitelaw F, Tait A, Gilleard JS, Jackson F. A survey of the trichostrongylid nematode species present on UK sheep farms and associated anthelmintic control practices. Vet Parasitol. 2012;189:299-307.

18. Demeler J, Schein E, von Samson-Himmelstjerna G. Advances in laboratory diagnosis of parasitic infections of sheep. Vet Parasitol. 2012;189:52-64.

19. Roeber F, Jex AR, Campbell AJ, Nielsen R, Anderson GA, Stanley KK, Gasser RB. Establishment of a robotic, high-throughput platform for the specific diagnosis of gastrointestinal nematode infections in sheep. Int $J$ Parasitol. 2012;42:1151-8.

20. Roeber F, Jex AR, Gasser RB. Advances in the diagnosis of key gastrointestinal nematode infections of livestock, with an emphasis on small ruminants. Biotechnol Adv 2013:31:1135-52

21. Boag B, Thomas RJ. Epidemiological studies on gastro-intestinal nematode parasites of sheep: the seasonal number of generations and succession of species. Res Vet Sci. 1977;22:62-7.

22. Bartley DJ, Jackson E, Johnston K, Coop RL, Mitchell GBB, Sales J, Jackson F. A survey of anthelmintic resistant nematode parasites in Scottish sheep flocks. Vet Parasitol. 2003;117:61-71.

23. Brunsdon RV. Seasonal changes in the level and composition of nematode worm burdens in young sheep. New Zeal J Agr Res. 1970;13:126-48.

24. Vlassoff A, Leathwick DM, Heath ACG. The epidemiology of nematode infections of sheep. New Zeal Vet J. 2001;49:213-21.

25. Morgan ER, van Dijk J. Climate and the epidemiology of gastrointestinal nematode infections of sheep in Europe. Vet Parasitol. 2012;189:8-14.

26. Jackson F, Jackson E, Coop RL, Huntley J. Interactions between Teladorsagia circumcincta and Trichostrongylus vitrinus infections in young lambs. Res Vet Sci. 1992:53:363-70.

27. Lello J, Boag B, Fenton A, Stevenson IR, Hudson PJ. Competition and mutualism among the gut helminths of a mammalian host. Nature (London). 2004;428(6985):840-4.

28. Sykes AR. Parasitism and production in food animals. Anim Prod. 1994;59:155-92 
29. Bartley DJ, Donnan AA, Jackson E, Sargison N, Mitchell GBB, Jackson F. A small scale survey of ivermectin resistance in sheep nematodes using the faecal egg count reduction test on samples collected from Scottish sheep. Vet Parasitol. 2006;137:112-8.

30. Bott NJ, Campbell BE, Beveridge I, Chilton NB, Rees D, Hunt PW, Gasser RB. A combined microscopic-molecular method for the diagnosis of strongylid infections in sheep. Int J Parasitol. 2009;39:1277-87.

Submit your next manuscript to BioMed Central and we will help you at every step:

- We accept pre-submission inquiries

- Our selector tool helps you to find the most relevant journal

- We provide round the clock customer support

- Convenient online submission

- Thorough peer review

- Inclusion in PubMed and all major indexing services

- Maximum visibility for your research

Submit your manuscript at www.biomedcentral.com/submit 